Dacia F. Dressen*

\title{
Identifying textual silence in scientific research articles: Recontextualizations of the field account in Geology
}

\begin{abstract}
Long neglected as a primary impetus of study, textual silences abound in such field disciplines as geology, where most field results seem to 'disappear' from the published research article. This paper first discusses the nature of textual silence and then proposes a typology of textual silences associated with written scientific discourse. Next, by examining the different disciplinary genres involved in the "recontextualizations" of a fieldwork study in geology, this study seeks to (1) identify textual silence in the various recontextualizations and (2) offer explanations for it.
\end{abstract}

\section{The 'said' and the 'unsaid' in scientific discourse}

The fundamental role played by "silences" in communication has been strongly underscored by a number of authors over the years. Hall (1985), for example, has observed that positively marked terms have meaning because of their relation to what is absent and unmarked. Ducrot (1973) argues that the relational link between the explicit and the implicit is made visible by the presuppositions underlying communicative acts. These implicit presuppositions allow for a set of conventions and laws to be seen within a language, and regulate individuals' interactions.

Becker (1995) also emphasizes the essential role played by silence, by noting that "speech consists above all in silences. A being who could not renounce saying many things would be incapable of speaking ... Each people leaves some things unsaid in order to be able to say others" (Becker 1995, p. 6). The act of communication therefore involves a pro-

* Dacia F. Dressen

12 , rue de la Malodière

F-63400 Chamalières

daciafd@wanadoo.fr

Hermes, Journal of Linguistics no. 28-2002 
82

cess of selection, of setting aside certain items which are "unsayable" in particular situations, either for structural reasons ("interlingual system constraints", Swales 1999), or because of the communally-constructed and culturally-determined context of silence (Swales' "intralingual ritual constraints"). Therefore, the process of selection is also highly dependent on the situated context of the communicative event.

Thus we see that within every communicative structure there exists a necessary complementarity between what is explicit and what is not. Silence is not a simple pause or absence of communication, but rather it has, like overt discourse, a functional role with its own meaning and interpretive value (see also Tannen \& Saville-Troike 1985, Jaworski 1993). This interpretive value is not immediately apparent, for it appears only after the hearer has "reconstructed" the speaker's intent on the basis of shared knowledge and assumptions. Over time, silences become a 'normalized' and 'anticipatable' part of the institutional framework that regulates communicative interactions. And finally, our capacity to use silences at appropriate moments and interpret the silences of others depends on our acculturation into a particular community. Indeed, "It only takes one person to produce speech, but it requires the cooperation of all to produce silence" (Pittenger et al. 1960)

And yet, despite the manifestation of such culturally-embedded, highlyconventionalized and community-generated instances of implicit communication, the discourse analysis of academic and research genres has to date focused largely on clearly identifiable text-types and visible text features, assuredly because what is most immediately accessible to the text researcher are not impalpable concepts like "communicative purpose" (see Askehave and Swales 2001 for a recent discussion) or "private intentions" (Bhatia 1997), but explicit linguistic form and content. Very little attention has in fact been paid to describing and accounting for the muted and tacit conventions of textual practices, despite Huckin's (1997) recommendation that the analysis of content should also include close attention to what is not said or written and Swales' (1998) observation that "genre analysis' most consistent lesson is the importance of noting elements that are unexpectedly missing from a text or discourse" (p. 151).

Two linguists have proposed typologies of the different silences one might find in communicative exchanges. Ducrot (1973) has identified 
two overarching types of silence in language: what is implicit within an utterance ("l'implicite de l'énoncé") and what is implicit within the act of speech ("l'implicite fondé sur l'énonciation, ou les sous-entendus du discours"; see also Ducrot 1969). In the first of the two, a speaker would say X but in so doing would in fact implicitly say Y. The implicit proposition is signaled by a gap within a chain of explicit utterances. However, its existence is concealed and is instantiated only because the hearer (or reader) is able to fill in the gap, thus requiring that a community of speakers or writers tacitly accept the proposition. In the second type of silence, the speaker's planned communicative act is subject to a set of conditions that influence the act of speech. This set must be met, for example, in order for the speaker to be granted the right to speak; if not, the speaker must manage to say what needs to be said indirectly, without having actually 'said' it.

In a recent paper, Huckin (2002) proposes a typology of "textual silences", which he defines as "the omission of some piece of information that is pertinent to the topic at hand". Among these, he includes: (1) 'Speech act silences': the speaker or writer intends for the silence to have communicative import, but the reader or listener can arrive at the intended understanding only because they all share a set of expectations. (2) 'Presuppositional silences': the speaker or writer may achieve greater communicative efficiency by not stating what is assumed to be common knowledge easily recoverable from context. (3) 'Discreet silences': the speaker avoids mentioning sensitive subjects conditioned by issues of confidentiality, tactfulness, or taboo topics. Ducrot (1973) similarly points to entire subjects (be they activities, feelings, or events) that are protected by 'a law of silence' so that if an individual were to talk about a particular subject, he would be considered to be bragging, complaining, offending someone, or humiliating himself or someone else. (4) 'Conventional silences': some silences are governed by genre conventions, as in research reports that routinely leave out methodological details. The inclusion of such "unnecessary" information would bring the investigator's role and activities into the foreground, thereby undermining the genre's aura of "machine-like objectivity" (Swales 1999). (5) 'Manipulative silences': the speaker/writer deliberately conceals relevant information from the reader or listener. (6) 'Incidental silences', or those that occur by accident and appear to have no particular purpose. 


\section{4}

While this typology effectively captures the socially-embedded facets of communicative silence, it also appears to dichotomize silence, perhaps unavoidably and necessarily so. The first four types in Huckin's system represent the community-conventionalized silences that rely on shared frames of reference and expectations. Shared background knowledge is a necessary precondition to the successful instantiation of speech act, presuppositional, discreet, or conventional silences. Community members must know and understand the implicit proposition and must themselves be able to manipulate this knowledge in order for the silences to be meaningful. The last two types fall into a different category and it would seem that the ability involved in identifying and comprehending them'manipulative' or 'incidental' silences - is less straightforward, relying instead on penetrating idiosyncratic communicative acts. The act of deliberately silencing certain parts of relevant information conceals the "probable" content of the original proposition, and uncovering it would entail gaining access to the ideologically motivated interests of specific communities, such as the journalistic milieu examined by Huckin (2002). As his corpus shows, images of the Homeless are often constructed in negative terms by the American media, where journalists routinely write about drug use, insanity or laziness as causes of Homelessness, only rarely making reference to other aspects of the problem. In other words, journalists tend, for ideological reasons, to 'silence' parts of the whole story.

As we might very well suspect by now, a genre's silences are determined not by its institutionalized context nor by its users' needs, but by both. And thus, it can be assumed that the silences that characterize newspaper articles differ from those of the specific part-genres of written scientific discourse. Therefore, an alternative descriptive typology of silence is proposed here, building on both Ducrot (1973) and Huckin (2002). Namely, it is suggested that there are three overarching levels of silence in written scientific discourse. The first is most accessible to members of a community, for it is generated by the structure of a particular discoursal system ("discursive system constraints"). The elements of this "institutionalized silence" have evolved over time within a set community of users whose thinking processes and cultural patterns are structured and unified by a process of "dialogized unity" (Bakhtin 1990). Over time, particular elements of the "possible repertoire" have been 
deselected through "intralingual ritual constraints" and therefore appear to no longer be a discoursal option. However, this de-selection process is the result of an unsuspected bias in the world picture painted by the community and its individual actors' habitus (Bourdieu 1984), and users unproblematically reduplicate it as "the way things are". This institutional silence constitutes what is expectedly missing and typically left unsaid in a text, for it is not considered relevant or pertinent to the particular community's needs.

The motivation for the second type of silence is less accessible than the first, as it originates from within the discursive system and represents the ongoing dynamic interplay between a "plures of individuals" (Miller 1993). As goal-oriented linguistic actions, these are "innovative and meaningful" silences that manipulate conventions in order to construct new and situated information. To do this, authors draw on a range of linguistic strategies to make claims more rhetorically present, but that do not bind them to the necessity of having to overtly state the claim and take responsibility for it (see Ducrot 1973). Here, the "private community needs" of a closely delimited community (e.g., "field geologists" or "mycologists") contrast with the wider and more general concerns of the larger community (e.g., "the geological research community", "biologists", "natural scientists", or "scientists"), and this motivates such instances of silence. Those motivated by "private individual needs" also fall into this category, as moments of unexpected and non-conventional linguistic innovation. Although the social structure may allow for its occurrence, it cannot condition its content, for it results from the transitory "need-state" (Artemeva \& Freedman 2001) of an individual on a particular occasion. While the manipulation of such silences may appear to result more in discretion than silence per se, such purposeful silences are characterized by their lack of linguistic explicitness. It is the very act of not saying that carries the propositional weight.

Finally, there are also unpredictable uses of silence, which because they occur randomly and do not appear conditioned by the social structures in which an individual operates, are the most occluded and difficult to identify. We can include here incidental or inadvertent silences (Huckin's accidental silences), which might occur when an individual who lacks full disciplinary knowledge about the conventionalized expressions in his given discourse domain, fails to "deselect" certain bits of information, 


\section{6}

thereby failing to appropriately observe what is typically left unsaid. Or, on the contrary, her or she may fail to mention what should be made overt. These silences will not further be dealt with here.

\section{1. "Institutional silences"}

Conventional omissions of research activity. Given its intended "discoursal objectivity", modern scientific discourse no longer allows inferences to the "nitty-gritty details" of the research activity. As we know from diachronic research, scientific discourse has evolved greatly over the course of the twentieth century (e.g., Bazerman 1988; SalagerMeyer 2000) and the research narrative has largely disappeared from scientific discourse, accompanied by an ever-growing increase in "authorial invisibility" (Salager-Meyer 1998). In this sense, one can talk about an evolution of communicative practice in which the scientist's methodological discourse has been silenced in written texts, such as we can see in biology (Gilbert \& Mulkay 1984; Myers 1990), physics (Bazerman 1988), medical discourse (Salager-Meyer 2000) or neurochemistry (Lynch 1985). Reporting on the non-empirical, experiential or "contingent" (Gilbert \& Mulkay 1984) details of research activities or events is today considered irrelevant.

Conventional imposition of personal modesty. In addition to the 'law of silence' imposed on reports of research activity, contemporary conventions also allow little or no personal implication on the part of the researcher, instead imposing an "appropriate authorial distance" between the research account and the writer. Thus if an author were to talk about his "feelings" or "personal experiences" as a researcher, he might very well be considered to be bragging, complaining, or perhaps even humiliating himself (see Ducrot 1973). For Gilbert and Mulkay (1984), the impersonality that characterizes this experiential discourse is generated by an "empiricist repertoire" that minimizes not only the author's actions, but also choices, judgments and beliefs (p. 42).

Dressen (1998) and Dressen and Swales (2000) have similarly pointed to the omissions made by writers of the fieldwork account in the geology research article. Here, geologists textually downplay the conditions of doing fieldwork as well as their own participation in the field mission. In spite of the obvious difficulties inherent in going out into the field, like the need to fend off attacks by wild animals, to have keen negotiating skills 
and be proficient in human and animal psychology (Scholz 1997), to be physically able to withstand the rigors of spending weeks or months in the field in extreme climates (N. Arnaud \& G. Chazot, pers. comm., 1999 ) and the resulting field culture of "rugged individuals" (Rudwick 1985), geological authors must today carefully avoid relating the sorts of 'Traveler's Tales' that were commonplace well into the first part of the twentieth century. It is obvious that all geologists must be silent about information like 'I got the rock despite the automatic rifle pointing at my back' or 'I slept badly because of the fleas'. Yet it is also these sorts of "just-part-of-the-job details" that motivate many field geologists' desire to do fieldwork and set them irrevocably apart from the "mere laboratory geologist". While such information is inappropriate within the conventions of the scientific article genre, it is not wholly irrelevant to the field geologist community, as evidenced by the fact that geologists frequently speak freely of their 'field experiences' at conferences, both in paper sessions as well as in the halls (Rowley-Jolivet 2000; M. Rudwick, pers. comm., 1999).

Economy of expression. Another type of conventional silence found in scientific discourse is engendered by shared disciplinarity and background knowledge. Latour and Woolgar (1979), for example, have pointed to omissions of 'given knowledge', which leave the impression that the research report is somehow incomplete (pp. 74-75). Berkenkotter and Huckin (1995) likewise refer to the role shared, established knowledge, or "tacit presuppositional knowledge" (p. 52), plays in the relative lack of explicitness in claims and warrants. This type of silence results in a "shorthand" enabling the writer to avoid having to go into detail about certain topics. A well-placed reference smartly embedded within a short phrase, for example, largely suffices for summarizing the key contributions a researcher has made and how they relate to the study at hand.

\section{2. "Innovative and meaningful silences"}

Rhetoric of understatement. There are also types of silence that stem not from the imposition of a social system's boundaries, but rather from a dynamic, goal-driven activity internal to the system (i.e., originating with a system's users). This is an activity driven by a particular "system internal" need, which can be either conventionalized or transient. So there are instances when the author uses a range of expressions, which while 


\section{8}

they may very well be conventionalized and accepted, translate the "private" need of a particular research community to draw special attention to a topic. However, as with unconventional omissions, this is done indirectly and the content remains inexplicit - at least to outsiders. Therefore, the propositional content here is purposeful, although "understated". An example can be found in systematic botany where the usual rhetorical exigency of establishing one's scientific reputation takes a back seat to "communal modesty", since a given research project may well outlast the life expectancy of its researchers. And so, when 'new' and therefore expectedly 'important' discoveries are made, they are indicated only discreetly in the research article by using a relatively short paragraph introduced by a small abbreviation - "sp. nov." (Swales 1998). Here we see one first illustration of Ducrot's (1973) range of discreet expressions used to make what is typically omitted known. While researchers cannot overtly declare their research a success, the implied content of 'sp. nov.' very clearly relates to the insider that the research is in fact a triumph.

A similar process is seen to occur in geology, where writers of field accounts in research articles must provide proof of physical presence in the field by rhetorically establishing their competence, credibility and authority as geologists through the description and interpretation of the field. However, given the exigencies of conventional omissions that downplay the field mission, today's authors cannot write explicitly about their field presence and so must make use of a subtle set of optional linguistic traces designed to suggest that the field description comes from the eyes of the author (Dressen 2001). These traces act as 'implicit' propositions that work to make the individual's participation in the research activity more clearly visible to members of his community.

Unconventional omissions. Just as there are speech act silences that depend on contextual or pragmatic cures, there are also silences marked by a nonconformity to Gricean maxims, in other words an unconventional or 'unexpected' omission. This reflects a transient need on the part of a writer or group of writers to manipulate expected conventions by replacing them with silence, such as in Huckin's (2002) manipulative silences in their failure to fully report on relevant information. A writer of a scientific article might evidence this type of silence by purposefully excluding the name of a certain researcher in his review of important work published in an area. These are purposeful silences 
motivated by personal intent - Bhatia's (1997) "private intentions" rather than by conventional expectations of silence. Such information is not expected to be kept silent, for others do not anticipate its presence. Rather, the author intentionally presents a version of the account that manipulates the function of silence in order to "implicitly" communicate new (i.e., non-conventional and unexpected) propositional content.

The concealed personal story. There are also instances when individual writers need to draw attention to their own story, but for reasons that remain entirely private. The conventionalized silences of modern scientific discourse do not permit writers to reveal their story in explicit terms, but we may very well find it in the use of unexpected details. For a geologist to write "During five summers, regional mapping of the entire Central Karakoram from Hunza in the west to Hushe in the east has been carried out" adds little relevant 'scientific' content to the proposition, but instead relates a transgression of the conventionalized silential boundary whereby the "personal and the heartfelt [are seen to] ruffle the smooth rhetorically machined textual surface" (Swales 1998, p. 80).

Using these silences as a backdrop for discussion, the purpose of this paper is to explain textual silence in the field account by examining the transformation of one geological fieldwork mission into its various textual and visual genres. It is assumed that the types of silences identified in geological field reporting are likely to be found in other instances of scientific writing, as well. All fields to some degree do give boiled-down and "distilled" versions of their research activity, of course, but geology, as a natural science, provides an exceptional window for studying silences given modern geologists' unusual and curious relationship to "the field as analytical object". On the one hand, field researchers are bound by the contemporary need to downplay the field mission. On the other, researchers must still "kowtow" to the positivist eye, indicating that they have been in the field so as to construct their credibility, authority and competence. What we are left with is a confined and muted discourse, needing to say much but without the - overt - means to say it. Here, the disciplinary framework for textual silence will be highlighted, for it is assumed that a genre's culturally embedded omissions are the area in which we may hope to find professional conventions most strongly at work. 


\section{Identifying and explaining textual silence: Theoretical approach}

What will be presented here are the results of a longitudinal and comparative analysis of the different genres produced by a doctoral student in geology. Studying the process by which a novice member to the geological community learns the elements of a community's "hidden dialogicality" (Bakhtin 1986) provides us with a particularly good opportunity to study textual silence, for the motivations for these silences are made more explicit as the student works through the various genres of his discipline (Parkinson 2000). By examining the fieldwork mission's "recontextualizations" (Linell 1998), we will see what today's geological community considers contextually inappropriate to the reporting of fieldwork.

Linell (1998) has described "recontextualization" as what occurs when some aspect of a genre is taken out from its original context and strategically embedded within a new genre, whereby the original event is creatively 're-presented', 're-produced' and 'mediated' through its relationship with prior discourse (Bourdieu 1991, Fairclough 1992). This paper will trace the recontextualizations of the field data collected by a French doctoral student, P., who spent two months in the field in the northern part of Madagascar with his dissertation advisor during the summer of 1999. As the first document, we will see excerpts in French of his field notebook from the field mission, which constitutes the basis for the analysis. As a second document, we will look at the transformation of his field results into visual form. Using his many field results, represented as notes, measures, photos, or different schemas, P. has fashioned a block diagram, which is a rectangular "cube" that synthetically and geometrically represents the earth's crust in three-dimensional perspective, with the top of the cube showing the ground and its sides providing the underlying geological structure (Bates \& Jackson 1984). This visual representation can be taken as a generic "text" in the sense that it represents a concrete discoursal unit and encompasses a set of visual conventions involved in the production of a standardized, visual, communicative event (see Rudwick 1976).

As a third document, we will look at excerpts of an abstract P. submitted to a conference about six months after the completion of his field mission. And finally, we will examine excerpts of a journal article recently approved 
for publication. In these texts, we will observe the transformation of P.'s field results at various stages and the role the institution plays in shaping exactly which results are - or are not - related to the scientific community.

\section{The field notebook: "Outcrop 129"}

The field notebook excerpts reproduced here represent one particularly fruitful day for P. and his advisor in their structural understanding of northern Madagascar, for on this day in a "gros niveau de gabbro" (Fig. 1a), they discovered a highly deformed outcrop characterized by numerous folds (Fig. 1b) both parallel (N120) and perpendicular (N50) to the lineation $^{2}$ (noted 'Lx'). In addition, they observed boudinage and double boudinage 3 , noted as "boudinage syn aplatissement" (Fig. 1c). According to P., for all these structures to be observed within one exposure is very rare, pointing to a very specific form of tectonic deformation in the region. P. and his advisor have therefore made an extremely important discovery, and this makes outcrop 129 a key element in the later recontextualizations of the field data, for P.'s interpretation of the region's geology largely hinges on the structures observed here.

1 Gabbro: A group of dark-colored, basic intrusive igneous rocks, equivalent to basalt. Lineation: A general term for any linear structure in a rock, e.g., flow lines or fold axes.

2 Boudinage: A structure found in strongly deformed sedimentary and metamorphic rocks, in which an original layer has been stretched, thinned, and broken at regular intervals into bodies resembling sausages.

3 Double boudinage: A simultaneous stretching in all directions, due to even pressure applied during widespread vertical compression, causes boudinaged prisms to separate into further boudins of the original prisms. Called "chocolate-block boudinage" in English. 
Figure 1. Excerpt from the field notebook. Outcrop 129 (August 1999)
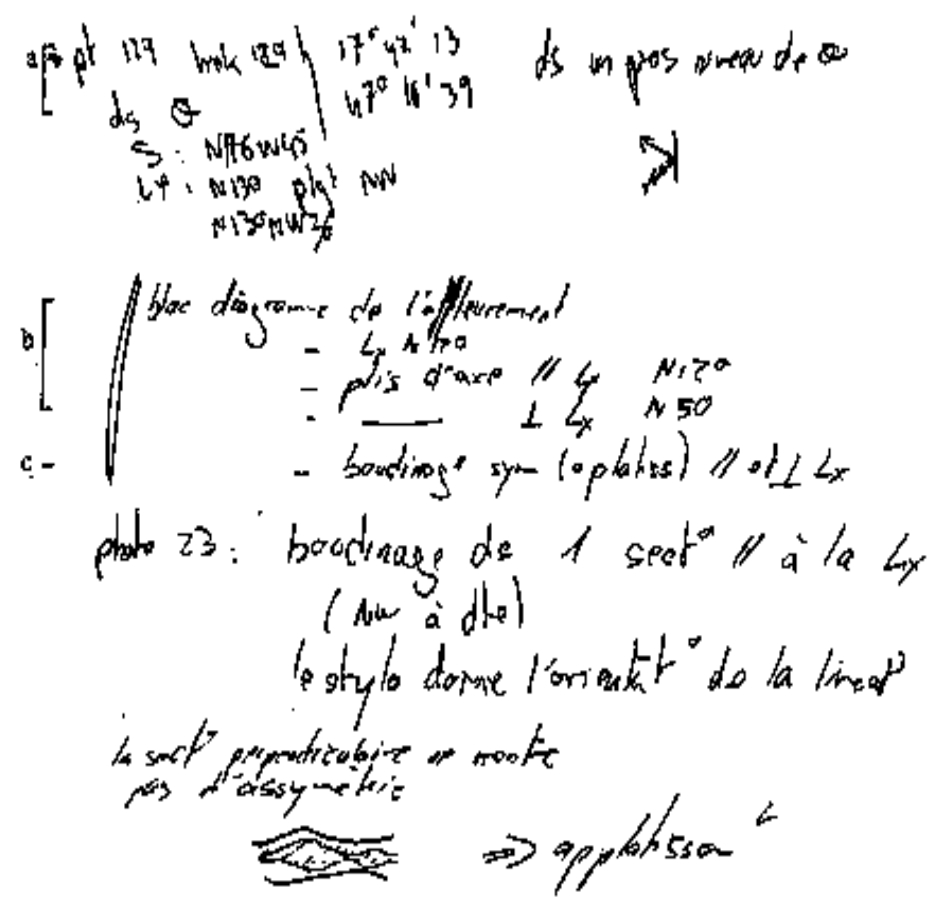

As we can see, the contents of the field notebook are really neither textual nor literary. Quite to the contrary, it is a type of document that brings together a mass of "private" information, exploitable only by its researcher. The traces of P.'s personal, physical, financial and intellectual investment are "locked into" his raw field data and later disappear from the visual representation and written texts, which are governed by the conventional omissions characteristic of modern scientific discourse. 


\section{The field observation recontextualized as a visual representation}

Since visuals are "cultural products" constructed by a given discourse community, they fulfill its communicative and ideological expectations (Kress \& van Leeuwen 1996). Lynch (1985) has observed this specific cultural orientation in visuals from neurobiology, where the researcher reorients the research account to retain only what he and his research community consider to be the most important aspects. Although the researcher purports to paint a picture of reality, the "rendering process" of the graph or chart in fact allows him to conceal various methodological glitches in the road and to discard them as irrelevant (Lynch 1985).

Similarly, geological observations made in the field are immediately framed within a conventionalized "visual language" (Rudwick 1976), and what geologists "see" - and don't see - is the product of a learned and communally-shared observational technique. Therefore, visuals such as geological maps, cross- and traverse-sections, block diagrams, or projections are compact, synthetic constructions that pull together a multitude of information in an extremely abstract, formalized and theoretical way, allowing geologists to conventionally and non-linguistically convey configurations that cannot be adequately expressed through words, numerical or mathematical symbols.

\subsection{The block diagram (August through October 1999)}

Here we will trace the recontextualization of P.'s field observations (see Fig. 1) as a block diagram. In a first schema drawn at his advisor's suggestion the very evening they discovered outcrop 129, P. indicates the various field data acquired so far: numerous fold axes perpendicular (N50) to the outcrop's lineation, double boudinage and various directional measurements. He puts his observations together in a simple schema with a good deal of textual support: "Dans première section parallèle à la linéation, on a également un plissement (axe des plis environ N50) ou perpendiculaire" (Fig. 2). Once he has done this, he proceeds to capitalize on his newly acquired conceptual understanding of the regional structure by redrawing the block in more conventional form. 


\section{4}

Figure 2. First block-diagram, drawn in the field (August 1999)

Over the next couple of months following the field mission, P. recrafts the communicative impact of this block diagram, keeping the same general structure. He adds a few textual notations, such as the double boudinage and various lithologies observed in the field (e.g., gneiss à bio, pegmatites, métabasite), and orientational measurements of the lineation (N120) and the folds and their type: down-folds (synforms) and up-folds (antiforms) ${ }^{4}$. The schema reproduced in Figure 3 (see below), a "finished" version of his block diagram, represents a sophisticatedly abstract and conventional synthesis of P.'s most important field results where he conveys the peculiar and exceptional nature of the region's tectonic regimes unveiled at outcrop 129. In this form, the results can be economically communicated to other members of his community.

4 Antiform: Up-fold with the oldest strata observed toward the top; Synform: Downfold.

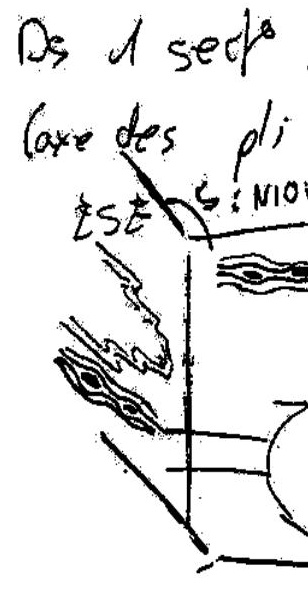


Figure 3. Polished version of the block diagram (September through October 1999)

Importantly, in this polished visual representation we can observe a

" "distillation" of the various measurements, lithologies and structures into one highly theoreticat and abstract, linguistically and cognitively economical image We, of course, also lose the specificity of the prized outcrop, despite the fact that subsequent-recontextualizations directly depend its plis $\mathrm{P1}$ à axes (Very important discovery. Here, "visual" scientific reporting conventions linéation montsynthetically mitigate findings and their significance and outcrop 129 fades et un boudinagefriem the forefront. The success ith which thes block diagram conforms important dans sos the conventional omission of such information underscores the fact that P. was already "aking on the voice" of the professional geologist (see Schryer 2001).

pis PI à ares paralledes à la inélation (N120)

\section{Textual Silence and the Conference Abstract}

That said, of course one can hardly consider that the academic field mission is finished without the results also having been "verbally" communicated, in either oral or textual form, to the scientific community. We will therefore look next at the recontextualization of P.'s field data into an 
96

abstract he submitted for a French geology conference in March 2000, entitled 'La Tectonique Néoprotérozoïque du Centre Nord de Madagascar: Interaction entre forces aux limites et forces de volume'.

The Conference Abstract has been widely examined by various text researchers (Huckin 1987, Berkenkotter \& Huckin 1995, Santos 1996, Yakhontova 1998), and has been shown to be a "freestanding document" submitted months in advance of the actual conference (Swales \& Feak 2000). Because it must work to impress a review committee, it often spends the first half of the abstract simply justifying the topic, for the author's research space must be clearly and strongly delineated before moving on to the results. In addition, the second half of the abstract is dedicated to describing the research and relies heavily on metadiscoursal strategies (e.g., demonstrative "this") used to draw the reader's attention to the results and to produce an impression of "closeness and solidarity" between the reader and writer (Mauranen 1993).

Successful abstracts must necessarily include an element of novelty for the scientific community, what Huckin (1987) has called "news value". Therefore, its purpose is not only to "create a research space" for the researcher (Swales 1990), but also to persuade the review committee that the study is a valid one and responds to the types of questions currently raised by the research community ("interestingness and timeliness", Berkenkotter \& Huckin 1995, p. 115). It therefore presupposes a strong valorization of the study, or what Swales and Feak (2000) have termed "a selling job". This, then, is the particular genre framework within which P.'s field data are recontextualized, resulting in significant changes, as we will see here.

The selling aspect of this particular writing task is one that $\mathrm{P}$. recognized immediately. Since his field results were essentially devoid of interest for the general geological community due to their locally constrained "regionality", he was bound by the strategic obligation to reset the problems raised by his data into a larger context in order to attract the interest of the greatest number of geologists. The abstract, written in French, is relatively "standard" and conforms nicely to Yakhontova's (1998) proposed fivepart move structure for the Conference Abstract. The first paragraph outlines the field's current knowledge about certain tectonic events and their associated geological periods. Within the background, P. relates having identified a particular tectonic process in northern Madagascar typically 
associated with very old geological time (i.e., $4-2.5$ billion years ago), during much more recent times (only 580-500 million years ago). This element underscores the importance and novelty of the research contribution for such an occurrence would be quite unexpected and unusual, thus giving reason to believe that something radically new is to be learned.

The second paragraph focuses primarily on the presentation of P.'s field research, and uses a number of sentence-initial demonstratives to 'draw the reader in' (Mauranen 1993), such as 'Cette croûte' (s.8), 'Cette tectonique' (s.9), and 'Celui-ci' (s.10). The principal task here consists of presenting the field data collected within the study area, which P. has already named the 'Andriamena unit' (s. 7), as demonstrative proof for his interpretation. In the following sentences, he quickly summarizes some of the most important field results we have already seen, such as the particular rock types (granites, migmatites, basalts).

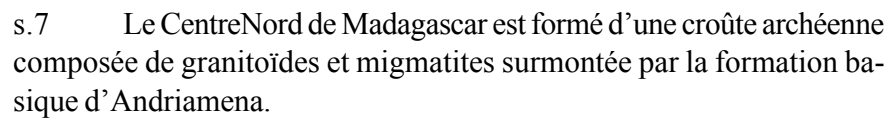

These field features are then set into a larger context where their importance - and novelty - is rhetorically highlighted (s. 8-9).

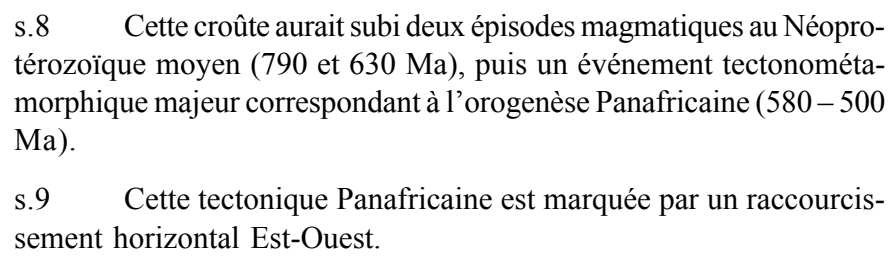

In s.8, P. notes that three geological events resulted in the features observed in the field. The most important of these for explaining the fold disorder seen at Outcrop 129 is horizontal compression ('raccourcissement horizontal Est-Ouest'; s. 9) circularly interpreted to have occurred on the basis of this field evidence. This compression is a key element in support of his 'novel' proposal, and as backing P. includes other field data to provide observational proof for the horizontal compression (s. 10 $-12)$.

s.10 Celui-ci est accommodé par des structures subméridiennes tel que des couloirs à fort gradient de déformation et un plissement de longueur d'onde variable correspondant à une succession d'antiformes granitoïdes et de synformes basiques (formation d'Andriamena). 
In sentence 10, we find other elements of the field data. The horizontal compression is in particular pointed to by intense folding ('des couloirs à fort gradient de déformation') that has occurred in the area, resulting first in fold axes oriented nearly due north-south ('sub-méridiennes', with an orientation N120-N130) and in synclinal and anticlinal folds ('un plissement de longueur d'onde variable'). The important implication here is that both ancient strata (granitic) and more recent strata (magmatic or basic) are found together at Andriamena in a "... succession d'antiformes granitoïdes et de synformes basiques", and this is taken to prove his interpretation. Finally, as further proof of this interpretation P. describes in sentence 12 a "décollement marqué par une zone mylontique" observed by him at the base of the Andriamena unit ('visible à la base').

Significantly, however, P.'s crucial observation of "boudinage" and "double boudinage" at outcrop number 129 (Figure 1b, c) receives no explicit reference here, although these structures played an equally important role in tipping P. and his advisor off that the particular tectonic event (East-West compression) had in fact occurred. Because the amount of field details is restricted by severe space limitations, pertinent results are chosen carefully to present the most convincing picture. As we can recall, these results were "rare", and although interesting not truly relevant. Thus there is a "hierarchization" of field results where rhetorically less convincing (i.e., pertinent and relevant) field features are set aside. While we might have expected the important boudinaged structures to have had their place here, the marshalling of field evidence in such rhetorically precise ways works less to give a precise description of the field than it does to prepare the audience for accepting the validity of his claim. As we can recall, this is considered to be one of the principal communicative purposes of the Conference Abstract. And thus, by complexly layering the most apparent and relevant evidence, $\mathrm{P}$. in fact prepares the way for making his singular, novel claim easier to accept.

As we can see, the notes taken from the field notebook and the details contained in the block diagram are strictly limited to a minimum of rhetorically "useful" and "permitted" details. From an abstract about 400 words in length, hardly a seventh (roughly 60 words) make reference to the results of the field mission. The two months that $\mathrm{P}$. has spent in the field are thus reduced to a mere handful of words, thereby showing the effects of genre-specific institutionalized silence on the shaping of this 
recontextualization. Here in particular we have seen a silence imposed by the need to explain something 'novel' in a strictly limited number of words. However, like 'sp. nov.', this is a rhetoric of understatement where a mere word or two to the wise suffices.

\section{Textual silence and the scientific research article}

In April 2001, P. submitted an article in English to appear in a special issue of Precambrian Research on some of the most recent structural research on Madagascar and the East-African plate. While the earlier abstract (March 2000) worked to woo a committee and emphasize what the largest number of geologists would find exciting and "novel", P. found himself here bound by a different set of communicative needs specific to field reporting in the research article, namely, (1) establishing his field presence and competence and (2) constructing strong and valid claims based on substantiated evidence.

And so, P.'s presentation of his data has changed to fit the communicative expectations of the new recontextualization. And his interpretation, for reasons of conventionality and convincibility, has been shaped into a new, more cohesive model that geologists working on the same part of the world will consider more relevant, reasonable and pertinent. P. is, after all, writing specifically for the regional specialists whose work is also to appear in the same issue. He is thus "fitting in" (see Rudwick 1996) so that his structural field discoveries will not go unpublished and eventually be lost.

The single, six-sentence paragraph where P. reports on outcrop 129 begins with a very rare, overt verbal reference to the research team, first with the passive ('can be observed') coupled with a set of evaluative adverbs ('more easily') in s. 1 , and then in s. 2 with the first-person plural pronoun ('we observe').

$$
\begin{aligned}
& \text { s. } 1 . \quad \text { Structures related to the } \mathrm{D} 1 \text { deformation can be observed more } \\
& \text { easily outside the high strain zones } \mathrm{D} 2 \text {. } \\
& \text { s. } 2 \text {. At the outcrop scale, we observe numerous isoclinal intra- } \\
& \text { folial folds with a hinge parallel to the L1 lineation and a sub- } \\
& \text { horizontal axial plane (Fig. } 3 \text { b-stereo a, b, c and Fig. 5). }
\end{aligned}
$$

In terms of explicit field data, in sentence 2 we also find reference to the outcrop's many folds ('numerous isoclinal intrafolial folds'). The term 
'isoclinal' 5 describes the folds that P. vividly illustrated in his block diagram (see Fig. 2). The hinges of these folds are here noted again to be parallel and perpendicular to the lineation (see 'plis d'axe // \& perp. à Lx N120' in Fig. 1b). In this same sentence (s. 2), P. also refers the reader to his block diagram in 'Fig. 5' in order to illustrate these structures (see Fig. 4 below).

In sentence 3 we at last find the unique reference to the term 'boudinage'. However, we will note here that the existence of boudinage and double ('chocolate-block') boudinage has been reduced in the text to the expression "boudinaged structures".

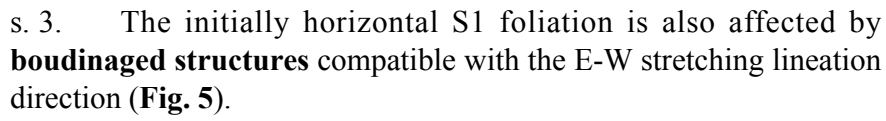

s. 3. The initially horizontal $\mathrm{S} 1$ foliation is also affected by boudinaged structures compatible with the $\mathrm{E}-\mathrm{W}$ stretching lineation direction (Fig. 5).

Apart from the caption accompanying 'Fig. 5', this is the only overt, textual reference to boudinage that occurs throughout the entire fieldwork report, 1850 words in length.

In sentence 4, P. uses these structures to establish his interpretation of events, introduced by the verbal phrase 'suggest + that' .

\section{s. 4. All these structures suggest that the D1 event underwent a} significant amount of vertical shortening.

This 'significant amount of vertical shortening', then, is one element of P.'s new interpretation, which consists of two major deformative geological events (D1 and D2). In sentence 5, P. returns to the difficulty in observing D1 features in the field, due to interference by the D2 deformation event. This interference once again highlights the importance of outcrop 129, where the D1 features were particularly visible. He then summarizes in the final sentence of the section (s. 6) how he arrived at the conclusion that the Andriamena unit had undergone an important D2 East-West compression, the second geological event.

And so, we can effectively see that, in P.'s words, "les données restent, l'interprétation change, beaucoup". He now has "vertical shortening" (D1) in addition to the "East-West compression" (D2) that we have seen in the abstract. His field data has remained largely intact, albeit in a distilled form. In conforming to genre expectations, the new interpretation

5 Isoclinal: Describes a fold whose limbs are parallel. 
here has been forced to downplay certain aspects of the field account, such as the 'forces de limite, forces de volume' of the abstract, or again the 'boudinaged structures' observed in the field. The textual reduction of the field account in the research article is thus attributable to the frame of this new recontextualization, which requires the author to shape and substantiate his claims more rigorously than in the conference abstract to fulfill the audience's expectations of a solid demonstration.

Of course, the reduction of the field account is also further explained by the fact that the block diagram has become the field data, making the 'textual' inclusion of details superfluous. Importantly, in the caption accompanying the block diagram, P. explicitly includes all the relevant field details we have previously seen in the field notebook, and has put all descriptive "text" in the caption (emphasis added on original caption). 
102

Figure 4. (P.'s "Fig. 5") "Schematic block diagram showing the different types of structures related to the D1 event, at outcrop scale. In the YZ section: isoclinal folds with axes parallel to the $\mathrm{L} 1$ lineation; in the $\mathrm{XZ}$ section: boudinage structures associated with scarce folds perpendicular to the $\mathrm{L} 1$ lineation; in the XY section: chocolate-block boudinage surface with a lineation L1. All these structures are consistent with a vertical shortening. The actual orientation of the block diagram is related to the later D2 folding. (1) biotite gneiss; (2) pegmatite; (3) metabasite."

It is remarkable and rare for a block diagram to have changed so little since the first sketch, and this highlights the ultimate importance the outcrop it describes took on during the process. In the end, however, it is questionable whether P. needed to include the block diagram to convince his readers of his interpretation. According to his advisors, this was "too 
much field talk" and they wanted him to get rid of it. There were other things P.'s advisors wanted to "censor" in his text, as well, such as the details of private conversations they had had which helped draw the interpretation together. While these details were relevant for P., his advisors considered them unnecessary and uncrucial for the argumentative structure of the paper.

Despite his advisors' success in convincing him to minimize the overt discussion of his interpretations' logic, P. held steadfastly onto the block diagram that had been with him since the start, thus pointing to an attachment P. seems to have developed toward it and the field data it recounts. Indeed, it directly translates his conception of the field that crystallized at outcrop 129, and the strength with which he subsequently took the block diagram to represent this field data frames his struggle to include it in this article. At the outset, it had allowed him to make sense of the incoherent lineations and intensely deformed folds he observed in the field. And of course, it was "the story" of that particular day spent in the field when P. was learning to successfully decipher the puzzles and mess of nature. And last, although hardly least, it was "his" creation, what was originally a homework assignment for the evening. As we can recall, P.'s advisor had asked him to sketch out a block diagram of their findings, and he hesitantly set to work. But through the process of recontextualizing what he had seen into a conceptually conventional form, P. himself understood what was going on and from that point on became an active owner and shaper of his field observations into suitable interpretation, moving yet a bit higher up on the novice-expert continuum.

In the silences of this final recontextualization, we can thus find the trace of P.'s attachment to his block diagram and to his fieldwork, for its inclusion here points to yet another type of silence: an unexpected, nonconventional, motivated silence, in other words, a concealed personal story. Indeed, there are times when the inclusion of what is conventionally omitted points to a silential expression whose sole purpose lies not in the communication of some 'relevant' information to the research community, but rather in giving voice to the author's personal experience. What might be considered a lack of modesty, according to Ducrot (1973), has here been entirely mediated by the visual's conventionalized framework, where such private intention remains unthreatening, for unseen. At most, the inclusion of a block diagram might be considered irrelevant and superfluous 


\section{4}

and thus discarded, but here the review committee has granted its presence. And so, while P.'s attachment to the block diagram remains wholly silent in his text, its mere presence is the key to unveiling its implied communicative content.

\section{Conclusion}

It is undeniable that part of learning to recontextualize the research account involves "taking on" the community's voice (see Schryer 2001). And thus we may often see junior researchers adopting a more standard discoursal distance between themselves and their research in order to demonstrate their desired recognition and membership to a new community. Nevertheless, we may also see them struggle with the decision to give up parts of the research account they consider important, but which are not validated by senior researchers as being pertinent or relevant for the construction of community knowledge. And thus we may see authorial space shift over time as the individual works within the bounds of conventionally appropriate and inappropriate content.

The comparative examination of recontextualizations may reveal silences from other disciplines, as well. Processes of recontextualization and its resulting silences have been described in reflexive ethnography, for example, where "textualization" is regarded as a rhetorical device for blurring the distinction between description and interpretation in the construction of social reality. Thus the transformation of fieldnotes into ethnographic texts is directly constrained by the assumed relation that exists with an ideal audience (Clifford and Marcus 1986). This process is also similar to the psychotherapist's practice of transforming casenotes into institutional records (Ravotas and Berkenkotter 1998; Berkenkotter 2001). In the process of producing a new text for a specifically targeted audience, the identity of the source text and its surrounding context are likely to be sacrificed, much in the way as we have seen for the geological field report.

\section{References}

Artemeva, N. and Freedman, A. (2001). "Just the boys playing on computers": An activity theory analysis of differences in the cultures of two engineering firms. Journal of Business and Technical Communication, 15(2): 164-194. 
Askehave, I. and Swales, J. (2001). Genre identification and communicative purpose: A problem and a possible solution. Applied Linguistics, 22(2): 195-212.

Bakhtin, M. (1986). Speech genres and other late essays. Austin: University of Texas Press.

- (1990). Art and answerability: Early philosophical. Austin: University of Texas Press.

Bates, R. and Jackson, J. (1984). Dictionary of Geological Terms, third edition. New York: Doubleday.

Bazerman, C. (1988). Shaping written knowledge: The genre and activity of the experimental article in science. Madison: University of Wisconsin Press.

Becker, A. (1995). Beyond translation. Ann Arbor, MI: University of Michigan Press.

Berkenkotter, C. (2001). Genre systems at work: DSM-IV and rhetorical recontextualization in psychotherapy paperwork. Written Communication, 18(3): 326-349.

Berkenkotter, C. and Huckin, T. (1995). Genre knowledge in disciplinary communication: Cognition/culture/power. Hillsdale, NJ: Lawrence Erlbaum.

Bhatia, V. (1997). Genre-mixing in academic introductions. English for Specific Purposes, 16: 181-195.

Bourdieu, P. (1984). Distinction: A social critique of the judgment of taste. Cambridge: Harvard University Press.

- (1991). Language and symbolic power. Cambridge: Harvard University Press.

Clifford, J. and Marcus, G. (1986). Writing culture: the poetics and politics of ethnography. Berkeley: University of California Press.

Dressen, D. (1998). Le cadre géologique dans l'article de géologie en français et en anglais: Crédibilité et retenue sur le terrain, ASp: la revue du GERAS, 19/22: 51-66.

Dressen, D. (2001). Textual silence in the Fieldwork Report: Modern geologists recounting the field mission in the scientific research article. Paper presented at the Genre2001 Conference: Genres and Discourses in Education, Work and Cultural Life, Oslo, Norway, 13 - 16 May 2001

Dressen, D. and Swales, J. (2000). "Geological setting/cadre géologique" in English and French petrology articles: Muted indications of explored places. In A. Trosberg (ed.), Analysing Professional Genres. Amsterdam: John Benjamins, 57-76.

Ducrot, O. (1969). Présupposés et sous-entendus. Langue française, 4: 30-43.

- (1973). Dire et ne pas dire: Principes de sémantique linguistique. Paris: Hermann.

Fairclough, N. (1992). Discourse and social change. Cambridge: Polity Press .

Gilbert, G. and Mulkay, M. (1984). Opening Pandora's box: A sociological analysis of scientific discourse. Cambridge: Cambridge University Press.

Hall, S. (1985). Signification, representation, ideology: Althusser and the post-structuralist debates'. Critical Studies in Mass Communication, 2: 91-114.

Huckin, T. (1987). Surprise value in scientific discourse. Paper presented at the CCC Convention, Atlanta, 1987. 
106

- (1997). Cultural aspects of genre knowledge. In A. Mauranen and K. Sajavaara (eds.), AILA Review, 12: 68-78.

- (2002). Textual silences and the discourse of homelessness. In Discourse and Society, 13(3).

Jaworski, A. (1993). The power of silence: Social and pragmatic perspectives. Newbury Park: Sage Publications.

Kress, G. and van Leeuwen, T. (1996). Reading images: The grammar of visual design. London: Routledge.

Latour, B. and Woolgar, S. (1979). Laboratory life: The social construction of scientific facts. Princeton, NJ: Princeton University Press.

Linell, P. (1998). Discourse across boundaries: On recontextualizations and the blending of voices in professional discourse. Text, 18(2): 143-157.

Lynch, M. (1985). Discipline and the material form of images: An analysis of scientific visibility. Social Studies of Science, 15: 37-66.

Mauranen, A. (1993). Contrastive ESP rhetoric: Metatext in Finnish-English economics texts. English for Specific Purposes, 12: 3-22.

Miller, C. (1993). Rhetoric and community: The problem of the one and the many. In T. Enos, S. Brown (eds.), Defining the New Rhetorics. Newbury Park: Sage Publications.

Myers, G. (1990). Writing biology: Texts in the social construction of scientific knowledge. Madison: University of Wisconsin Press.

Parkinson, J. (2000). Acquiring scientific literacy through content and genre: a themebased language course for science students. English for Specific Purposes, 19(4): 369387.

Pittenger, R., Hockett, C. and Danehy, J. (1960). The first five minutes: A sample of microscopic interview analysis. Ithaca, NY: Paul Martineau.

Ravotas, D. and Berkenkotter, C. (1998). Voices in the text: The uses of reported speech in a psychotherapist's notes and initial assessments. Text, 18(2): 211-239.

Rowley-Jolivet, E. (2000). The pivotal role of conference papers in the network of scientific communication. ASp: La revue du GERAS, 23/26: 179-196.

Rudwick, R. (1976). The emergence of a visual language for geological science, 17601840. History of Science, 14: 149-95.

- (1985). The great Devonian controversy: The shaping of scientific knowledge among gentlemanly specialists. Chicago: University of Chicago Press.

- (1996). Geological travel and theoretical innovation: The role of liminal experience. Social Studies of Science, 26: 143-59.

Salager-Meyer, F. (1998). Le discours aigre-doux de la controverse scientifique: Evolution de la rhétorique des confrontations académiques. ASp: La revue du GERAS, 19/22: 29-50.

- (2000). Rhetorical evolution of oppositional discourse in French academic writing: Oppositional discourse in academic writing. Hermes, 25: 23-48. 
Santos, M. Bittencourt dos. (1996). The textual organization of research paper abstracts in Applied Linguistics. Text, 16(4): 481-499.

Scholz, C. (1997). Fieldwork: A geologist's memoir of the Kalahari. Princeton, NJ: Princeton University Press.

Schryer, C. (2001). Structure and agency in the genre of case presentations. Paper presented at the Genre2001 Conference: Genres and Discourses in Education, Work and Cultural Life, Oslo, Norway, 13 - 16 May 2001.

Swales, J. (1990). Genre analysis: English in academic and research settings. Cambridge: Cambridge University Press.

- (1998). Other floors, other voices: A textography of a small university building. Mahwah, NJ: Lawrence Erlbaum.

- (1999). Textual silence: An approach to disciplinary cultures. Paper presented at Cornell University, June 1999.

Swales, J. and C. Feak. (2000). English in today's research world: A writing guide. Ann Arbor: University of Michigan Press.

Tannen, D. and Saville-Troike, M. (1985). Perspectives on silence. Norwood, NJ: Ablex.

Widdowson, H. (2000). On the limitations of linguistics applied. Applied Linguistics, 21(1): 3-25.

Yakhontova, T. (1998). Cultural variation in the genre of the conference abstract: rhetorical and linguistic dimensions. Paper presented at the Conference on English as a conference language, 14 - 17 January, Halle-Wittenberg, Germany. 


\section{When Talk is a Science...}

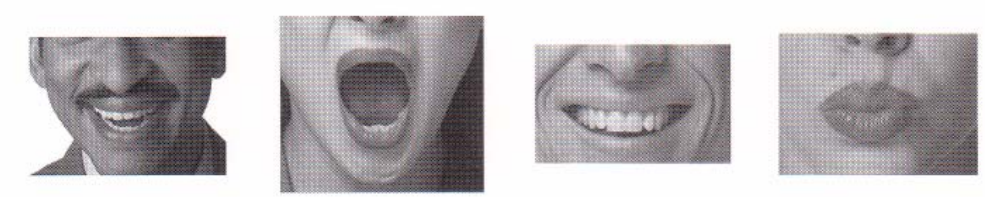

\section{Linguistics and Language Behavior Abstracts}

Comprehensive, cost-effective, timely coverage of current ideas in linguistics and language research

Abstracts of articles, books, and conference papers from nearly 1,500 journals published in 35 countries; citations of relevant dissertations as well as books and other media.

Available in print or electronically through the Internet Database Service from Cambridge Scientific Abstracts (www.csa.com).

Contact sales@csa.com for trial Internet access or a sample issue.

\section{Linguistics \& Language Behavior Abstracts}

Published by CSA 